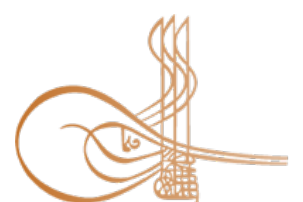

www.turkishstudies.net/economy
Turkish Studies - Economics, Finance, Politics

eISSN: $2667-5625$

Research Article / Araștırma Makalesi

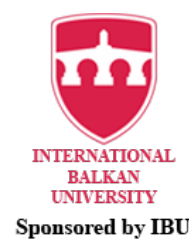

Sponsored by IBU

\title{
Yeni Ekonomi Programı Çerçevesinde (2020-2022) Girişimcilere Yönelik Yeni Nesil Bir Finansman Yöntemi: Kitle Fonlaması
}

\author{
Within The Scope Of New Economy Program (2002-2022) A New Generation Financing Approach \\ For Entrepreneurs: Crowd Funding
}

\author{
Nevzat Tetik
}

\begin{abstract}
With the action plans created in the Medium Term New Economy Program by the Ministry of Treasury and Finance of Republic of Turkey, shaped with the main theme of "Interchange Begins" embracing the years 2020-2022, it is proposed transition to a new economic model would create a powerful Turkey. In the major topic of this program as financial stability, during the program period to strengthen and ensure financial stability, the steps to be taken under the subtitle of policies and measures are listed systematically. The point is the question of these policies and measures is aimed to create a modern next-generation finance channel under the name of crowd funding for the financing of innovative projects by encouraging digital transformation for would be a solution to the financing problems of entrepreneurs who are the main pillar of the country's development. The term of crowd funding is a financial approach which could be expressed as fund raising method for entrepreneurs who have trouble finding financial resources for the funds they need. This financial approach bands together by gathering small amounts of funds from general masses for entrepreneurs. The crowd funding approach is an alternative financial method for Turkish entrepreneurs which have been applied around the world since end of 1990's. In Turkey, it has increased the practice field at small sizes in 2010. With the New Economy Program, Turkish entrepreneurs have been encouraged for using crowd funding approach. Consequently, it is essential to examine with including all dimensions for the purpose of informing the public for this quite new application for entrepreneurs. In this study, we give general information about crowd funding for expecting awareness in Turkey. We study to improve and evaluation the system in a healthy manner and try to develop proposal. In this context, crowd funding which is a reflection of Turkey's development move, should use an opportunity, it is extremely important to establish an effective supervision system by making legal arrangements immediately with the necessary regulations and revisions in line with the current conditions. Besides, in the lack of knowledge and experience arising from the fact that this financing method is quite new, we speculate that it would be useful for making up the shortage, organizing contact meetings and distribution of introductory brochures and booklets to the public by experts and institutions whom qualified on this field.
\end{abstract}

Structured Abstract: Today, entrepreneurs' most important issue is the handicap of finding funds available just in time and with an optimal cost. The legal authorities of the countries around the world with the purpose

* Doç. Dr., İnönü Üniversitesi, İktisadi ve İdari Bilimler Fakültesi, İşletme Bölümü
Associate Professor, Inonu University, Faculty of Economics and Administrative Sciences, Department of Business
Administration
ORCiD 0000-0002-3152-8217
ntetik44@hotmail.com
Cite as/ Atıf: Tetik, N. (2020). Yeni ekonomi programı çerçevesinde (2020-2022) girişimcilere yönelik yeni nesil bir
finansman yöntemi: Kitle fonlamas1. Turkish Studies - Economy, 15(2), 925-940.

finansman yöntemi: Kitle fonlamas1.
https://dx.doi.org/10.29228/TurkishStudies.41964

Received/Geliş: 29 February/Şubat 2020

Accepted/Kabul: 20 June/Haziran 2020

Copyright (C) INTAC LTD, Turkey

Checked by plagiarism software

Published/Yayın: 25 June/Haziran 2020

CC BY-NC 4.0 
of finding a solution for that issue, make different backstopping and inducement on legal, financial and technical ways. In recent years, for the entrepreneurs in Turkey are seen as a development engine, the legal authorities take certain steps for making aid to increase the numbers rapidly and eliminate the problems they may encounter. The first step of these arrangements is the Medium Term New Economy Program including the years 2020-2022 created by the Ministry of Treasury and Finance of the Republic of Turkey. Under the New Economic Program's financial stability main topic, during the program period the actions to be taken to strengthen and ensure financial stability, the subtitle of policies and measures are listed systemically. One of aforesaid policies and measures is aimed to create a modern next-generation finance channel under the name of crowdfunding for the financing of innovative projects by encouraging digital transformation for would be a solution to the financing problems of entrepreneurs. Concordantly, In this study, we give general information about crowdfunding around the world for increasing awareness in Turkey and make improve and evaluate to able to work the system healthily and try to develop a proposal.

The crowdfunding is the process of masses coming together to fund an idea, project or need with small donations, in the narrowest sense. In a broad sense, crowdfunding could be expressed as a fundraising method for entrepreneurs who have trouble finding financial resources for in need of funds by banding together gathering small amounts of funds from general masses for entrepreneurs. Although there are different applications in the world, in general, there are four different types of crowdfunding: donation-based, rewardbased, borrowing based and partnership-based.

The donation-based funding model works in the form of collecting donations made by other people through crowdfunding organizations and delivering these donations to the project owner after individuals design the funds they need and announce over the internet. In the reward-based funding model, which is used quite frequently among crowdfunding models, there is no relevant to buying or selling any securities. In this model, the individual or business that collects funds for its project promise to give the predetermined assuming prize to the funders, if the project achieves the desired success. The assuming prize could be in a large range likewise a thank call, a T-shirt, a book or giving the names on the preface. The borrowing-based funding model provides finding funds to the project or business owners whose in demand of fund from the funders in the way of credits or debts, as like function of microcredit system, through crowdfunding platforms within the framework of a certain maturity date and interest according to the amount of funds they need. The partnerbased funding model is also called share or allocation- based funding model. Generally, the amount of funds needed is determined as a certain limit by the entrepreneur who needs financing and the investment is implemented by providing the figure determined at the optimal time through crowdfunding. In the partnershipbased funding model, through the platform where the fund would be collected, various data and information are shared with the investors and the businesses on the valuation of the business, the business plan, the possible use of the fund, and how much of the partner's interest are offered for sale. With this model, a fairly high amount of financing could be achieved by reaching a large investor mass.

The crowdfunding approach has been seen as an alternative financing method for Turkish entrepreneurs which has been applied around the world since the end of the 1990s. In Turkey, it has increased the practice field at small sizes in 2010. Two legislative arrangements were made by the Capital Markets Board on 5th December 2017 and 3rd October 2019, in order to ensure that crowdfunding is widely practiced legally and effectively. We assume that the finding below should be considered and it would be right to make the necessary arrangements and activities immediately for entrepreneurs in Turkey to use actively these facilities at the desired level.

1- $\quad$ Although the crowdfunding method engages and well known spreadly around the world, it is a very low awareness phenomenon in Turkey. When it is considered from this point of view, with the purpose of equipping the entrepreneurs with healthy and updated information, it would be befitting activity to distribute advertisement brochures and booklets to the public and arranging conferences and meetings by experts on crowdfunding.

2- $\quad$ Gaining the crowdfunding model legal status is an extremely important development. Certainly, it is quite important and mandatory that the Capital Markets Board of Turkey should have revised the regulations on crowdfunding with the consideration of today's developments and conditions for the development of the model in the long-run, point blankly. 
3- $\quad$ The borrowing-based crowdfunding model, which is widely used by entrepreneurs in the world, is not included in Turkey's legislation. It might be expected an increase in the number of entrepreneurs in Turkey if the legislators in Turkey could have made the adaption of the system on the way getting in contact with the countries, which already use the borrowing-based crowdfunding successfully and professionally.

4- $\quad$ The crowdfunding brings in through the risk of financial fraud as a result of being online fintech reflex. Therefore, it would bring possible positive effects on increasing the number of entrepreneurs by the active control and sanction of the legislators in practice for working in the safety of the system.

5- There are difficulties in finding accurate information about the current number of crowdfunding platforms and projects' trading volumes in Turkey. In this situation could bring misconduct and fraud together between the crowdfunding's parties. Besides, there are quite few numbers of empirical studies in the title of crowdfunding in Turkish literature. It is in need of reliable data for rational evaluation and analyses. When viewed from this aspect, we foresee that creating a shared network with the public about crowdfunding activities, transaction volumes, and project types, would contribute to the spread of crowdfunding effectively and efficiently.

The next studies on the main themes of crowdfunding might be theoretical or empirical studies shaped by the findings obtained in the framework of the new regulations in the Capital Market Law of Turkey and the impact of the crowdfunding model, which is particularly encouraged in the New Economy Program.

Keywords: Financing, Economy Program, Entrepreneurship, Crowd Funding, Financing Method.

Öz: T.C. Hazine ve Maliye Bakanlığı tarafından 2020-2022 yıllarını kapsayan "Değişim Başlıyor" ana temasıyla şekillenen Orta Vadeli Yeni Ekonomi Programında oluşturulan eylem planlarıyla güçlü Türkiye'yi oluşturacak yeni bir ekonomik modele geçiş öngörülmektedir. Bu programın finansal istikrar ana başlığında, program dönemi boyunca finansal istikrarın sağlanarak güçlendirilmesi amaciyla politika ve tedbirler alt başlı̆ıında atılacak adımlar sistematik olarak sıralanmıştır. Söz konusu politika ve tedbirlerden birisi de ülke kalkınmasının temel direğini oluşturan girişimcilerin finansman sorunlarına çare olabilecek, dijital dönüşüm teşvik edilerek yenilikçi projelerin finansmanı için kitle fonlaması (crowdfunding ) adı altında çağdaş yeni nesil bir finansman kanalı oluşturmak hedeflenmektedir. İngilizce karşılığı crowdfunding olan kitle fonlaması finansman yöntemi kısaca, finansal kaynak bulmada sorun yaşayan girişimcilerin ihtiyaçları oldukları fonları genel kitlelerin küçük oranlardaki fonlarını bir araya getirerek oluşturdukları fon toplama yöntemi olarak ifade edilebilir. Ülkemiz girişimcileri için önemli bir alternatif finansman yöntem olacağı düşünülen kitle fonlaması yöntemi dünyada 1990'lı yılların sonlarından itibaren uygulanmaktadır. Türkiye'de ise 2010 yılında küçük boyutlarda uygulama sahasına çıkmışıtır. Söz konusu Yeni Ekonomi Programı ile girişimcilerin kitle fonlaması modelini kullanmaları teşvik edilmektedir. Dolayısıyla girişimciler için oldukça yeni bir uygulama olan kitle fonlaması yönteminin bütün boyutlarıyla ele alınarak irdelenmesi ve kamuoyunun bilgilendirilmesi zaruridir. Çalışmada, dünyada kitle fonlaması hakkında genel bilgilere yer verilerek ülkemizde farkındalığının artırılması ve sistemin sağlıklı bir şekilde işleyebilmesi için değerlendirmeler yapılıp öneriler geliştirilmeye çalışılmıştır. Bu bağlamda, ülkemizin kalkınma hamlesinin bir yansıması olan kitle fonlaması uygulamasının firsatının iyi değerlendirilmesi, günün şartlarına paralel gerekli regülasyon ve revizelerle yasal düzenlemelerin ivedilikle yapılarak etkin bir denetim sisteminin tesis edilmesi son derece önemlidir. Ayrıca bu finansman yönteminin oldukça yeni olmasından kaynaklanan bilgi ve tecrübe eksiklerinin giderilmesi amacıyla sahanın uzman kişi ve kurumları tarafından bilgilendirme ve tanıtım toplantılarının aktif bir şekilde yapılması, kamuoyuna tanıtıcı broşür ve kitapçıkların dağıtılması yararlı olacağı düşünülmektedir.

Anahtar Kelimeler: Finansman, Ekonomi Programı, Girişimcilik, Kitle Fonlaması, Finansman Yöntemi.

\section{Giriş}

Dünya genelinde girişimcilerin en önemli sorunlarından birisi de zamanında ve optimal maliyetli finansal kaynak bulmaktır. Özellikle 2008 küresel finansal krizin beraberinde getirdiği finansal sistemin işleyiş mekanizmasındaki aksaklıklar, belirsizlikler, muhtemel yeni krizler ve riskler girişimcileri finansal darboğaza düşürmüştür. Diğer taraftan ülkemiz gibi gelişmekte olan ülkelerin yüksek katma değerli yeni yatırımlara yönelerek ekonomik kalkınma hamlelerini 
artırmaları için geleneksel bankacılık ve finansal enstrümanlardan sıyrılarak günün şartlarına uygun geniş yelpazede alternatif yeni finansman seçeneklerinin oluşturması kaçınılmaz olmuştur. Finansal sistem içesinde alternatif yeni nesil finansal kurum ve araçların zenginleştirilmesi politika yapıcıların ellerini güçlendireceği gibi girişimcileri de kuşkusuz rahatlatacaktır.

T.C. Hazine ve Maliye Bakanlığı tarafından 2020-2022 yıllarını kapsayan "Değişim Başlıyor" ana temasıyla şekillenen Orta Vadeli Yeni Ekonomi Programında oluşturulan eylem planlarıyla yeni bir başarı hikayesi yazmak amacıyla güçlü Türkiye'yi oluşturacak modern ekonomik modele geçiş öngörülmektedir. Bu programın finansal istikrar ana başlığında program dönemi boyunca finansal istikrarın sağlanarak güçlendirilmesi amacıyla politika ve tedbirler alt başlığında atılacak adımlar sistematik olarak sıralanmaktadır. Söz konusu politika ve tedbirler başlığında ' Kitle fonlaması uygulaması ile yatırımcılar için alternatif bir yatırım kanalı, girişimciler için de yeni bir finansman kanalı oluşturulacaktır " ( http://www.bumko.gov.tr ) ifadesiyle kitle fonlaması finansman yöntemine ayrı bir önem verilerek dikkat çekildiği gözlenmektedir. Ülkemizdeki özellikle küçük girişimcilerin geçmişten gelen alışkanlıklar ile çoğunlukla finansal kaynak arayışlarını konvansiyonel bankacılık ve finansman ürünleri çerçevesinde yaptıkları düşünüldügünde yeni nesil kitle fonlaması yönteminin kamuoyuna tanıtılmasının etkin şekilde yapılarak yaygınlaştırılmasının sağlaması ne kadar önemli olduğu açıktır.

İngilizce karşılığı crowdfunding olan kitlesel fonlaması finansman yöntemi kısaca, finansal kaynak bulmada sorun yaşayan girişimcilerin ihtiyaçları oldukları fonları genel kitlelerin küçük oranlardaki fonlarını bir araya getirerek oluşturdukları fon toplama yöntemi olarak ifade edilebilir. Ülkemiz girişimcileri için önemli bir alternatif finansman yöntem olacağı öngörülen kitle fonlaması yöntemi dünyada 1990'lardan itibaren uygulanmaktadır. Türkiye'de ise 2010 yılında küçük boyutlarda uygulama sahasına girmiştir (Vural ve Doğan, 2019: 89).

Gelişmiş ülkelerde bile özellikle girişimciler için oldukça yeni olan kitlesel fonlama uygulaması, akademik yazında da bilimsel olarak inceleme ve araştırmalar açısından oldukça yeni bir olgudur. Dolayısıyla yapılan çalışmalar da oldukça sınırlı sayıdadır (Mollick, 2012:2). Dünya'daki literatüre baktığımızda kitlesel fonlama kavramını bilimsel olarak ilk defa Jeff Howe ve Mark Robinson 2006 yılında Wired dergisinde işlemişlerdir (Solak ve Faydal1, 2018: 292). Belflamme vd. (2014) kitlesel fonlamayı girişimciler için yeni bir finans-man olarak incelemişlerdir. Mitra'da 2012 yılında yaptı̆̆ girişimciler için yeni modern bir finansal kaynak olduğunu kaydetmiştir (Çubukçu, 2017: 160).

Ülkemizde söz konusu Yeni Ekonomi Programı ile girişimcilerin kitle fonlaması modelini kullanmaları teşvik edilmekte ve özendirici adımlar atılmaktadır. Bu bağlamda, ülkemiz girişimciler için oldukça yeni bir finansal ürün olan kitle fonlaması yönteminin öneminin, dünyada ortaya çıkış1 ve gelişimi ile birlikte ülkemizde ki uygulama boyutlarının yasal zemin ve koşullarının kuramsal çerçevede ele alınarak irdelenmesi ve kamuoyunun bilgilendirilmesi çalışmanın temel amaçlarındandır.

\section{Dünyada Kitle Fonlaması Yönteminin Ortaya Çıkışı ve Gelişim Trendi}

Ülkemizde finans literatüründe yeni bir kavram olarak yer almaya başlayan alan kitle fonlaması finansman yöntemi ingilizce "crowdfunding" kelimesinden türetilmiştir. Aslında "crowdfunding" kelimesinin tam türkçe karşılığı kalabalık fonlamasıdır. Yani birden fazla insanın bir araya gelerek fonlarını birleştirmesidir. En dar anlamda kitle fonlaması, kitlelerin bir araya gelerek bir fikir, proje veya ihtiyacı küçük bağışlarla fonlaması işlemidir. Daha geniş anlamıyla, fon bulmayı oldukça kolaylaştıran müşteri, yatırımcı ve girişimcileri ortak iş yapma ve karş1lıklı iletişimle kazan-kazan iş ilişkisi kurmaya teşvik eden, çoğunluğu dijital internet platformları üzerinden ve belli bir zaman dilimlerinde yürütülen fonlama ve kampanya sürecidir. Başka bir açıdan kitle fonlaması, genellikle internet aracılığı ile finansal kaynak bulmak için kullanılan kamuya açık bir çağrı mekanizmasıdır. Diğer bir ifadeyle kitle fonlaması, finansman ihtiyacına konu olan fikir ve 
projeleri sunanlar ile bu fikir ve projelere inanıp destek olan veya olmak isteyen potansiyel bireylerin kitlesel fonlama platformu olarak isimlendirilen sitelerde buluşma sistemi olarak tanımlanmaktadır (İşler, 2014: 51). Üniversite harçlarını ödeyemeyen öğrencilerden acil tedavisi gereken hastalara, hayvan hakları savunucularından yeni iş ve girişimcilik fikirlerine kadar çok geniş bir sahada yaygın olarak kullanılan söz konusu yeni nesil finansal enstrüman milenyumun önemli yeniliklerinden biridir (Bağış, 2019: 20).

Tarihi süreç içersinde dikkat edilirse görülecektir ki kitle fonlaması göründüğü gibi aslında tam anlamıyla yeni bir kavram da değildir. 18.yüzyılda yazarlar ve müzisyenler eserlerini dünya çapında yayabilmek için çok sayıda yatırımcıdan para toplamaktaydı. Günümüzde ise başta sivil toplum kuruluşları olmak üzere bir çok kurum ve kuruluş toplumsal bir projeyi hayata geçirmek için özellikle etkin bir iletişim ve paylaşım ağı olan internetin de katkısı ile daha büyük bir kitleye ulaşarak fonlar toplayabilmektedir. Bu açıdan bakıldığında, kitle fonlaması geleneksel bağış ve fon toplama faaliyetlerinin günümüz şartlarına uygun olarak modernize edilmiş versiyonu olarak isimlendirilebilir (https://medium.com/)

$\mathrm{Bu}$ paylaşım odaklı sistemin yeni nesil modern finansman yöntem olarak ortaya çıkışı ise internetin toplumun tüm ekonomik birimlerinde kullanılmaya başlamasıyla gerçekleşmiştir. Günümüzde kitle fonlamasının ilk örnekleri bireylerin yardım amaçlı fonlamaları olmakla birlikte ilerleyen zamanlarda müzik albümleri, filmler, kitaplar, kampanyalar, geziler, bilimsel araştırmalar ve ürün finansmanı gibi çok sayıda farklı projeleri desteklemek tarzında da olmaktadır (Beaulieu vd., 2015: 5). İngiliz rock müzik grubu Marillion'un 1997 y1lında ABD turnesi için ihtiyaç duyduğu altmış bin doları internet üzerinden takipçileri tarafından düzenlenen bağış kampanyası ile toplaması, kitlesel fonlamanın ilk ve en basit örneğidir. Grup bu alternatif finansman kaynağının başarısını daha sonra çıkardığı üç albümü de aynı yöntemle finanse ederek kanıtlamıştır. Aynı amaçla, başta müzisyenler olmak üzere sanatçıları desteklemek hedefiyle, 2000 yılında kurulan ABD merkezli "ArtistShare" ise kitle fonlaması yöntemini kullanan ilk internet sitesi olarak tarihe geçmiştir. Ayrıca bu başarılı uygulama ile on altı Grammy adayı sanatçının ve üç Grammy ödüllü sanatçının sanatlarını icra etmek için fon bulmasına aracılık etmiştir (Sakızlı, 2018:7).

Dünya'da kitle fonlaması yönteminin yaygınlık kazanmasında özellikle küresel düzeyde yaşanan ABD kaynaklı 2008 küresel finansal krizin etkisi şüphesiz çok olmuştur. Küçük ölçekli ve erken aşama işletmelerin finansman bulmakta zorlanmasına kitle fonlaması yöntemi kurtarıcı rolünü üstlenmiştir. Diğer taraftan, geleneksel bankaların küçük işletmeleri riskli sınıfına alması ve kredi vermek istememesi, küçük ölçekli yatırımlar için finansman maliyetinin yüksek oranlarda seyretmesi, kriz ortamında pek çok kişinin yardımlaşma taraftarı olması, internetin finansman bulma, alışveriş yapma, bağı̧̧ toplama ve geniş kitlelere erişimini son derece kolay duruma getirmesi kitle fonlamasının kısa sürede yaygınlaşmasını sağlamıştır (Onur ve Değirmenci, 2015: 1).

Günümüzde kitlesel fonlama çoğu ülkede hızla büyümektedir. Fransa, İtalya, İngiltere gibi bir çok ülkede kitlesel fonlama ile ilgili düzenlemeler yürürlüğe konulmuş, Amerikan Sermaye Piyasaları Düzenleyici Otoritesi olan Securities and Exchange Commission (SEC) tarafindan yapılan düzenleme 2016 yılından itibaren yürürlüğe girmiştir ( Sakarya ve Bezirgan, 2018: 22). Dünyada oldukça popüler olan kitlesel fonlama platformları, şimdiye kadar birçok projeye destek olmuştur. En çok bilinen kitlesel fonlama sitelerinden biri olan Kickstarter kurulduğu günden bugüne kadar 147.370 projeyi fonlamış ve yaklaşık 4 milyar dolar para toplanmıştır. Dünya'da kitlesel fonlama platformlarının sayısı 2015 yılı itibariyle 2.902 'dir ve tüm bu kitlesel fonlama platformları aracilığ 1 ile toplanan paranın 2015 yılı itibariyle 34 milyar dolara ulaşmıştır. Türkiye'de dört kitlesel fonlama platformları aracılığı ile şimdiye kadar toplanan toplam miktar 7 milyon TL'ye yaklaşmış durumdadır. Toplam desteklenen proje sayısı ise 181'dir. Türkiye'de henüz yeni gelişmekte olan bir model için 181 projenin desteklenmesi oldukça memnuniyet verici bir gelişmedir. (Ekonomistler Derneği, 2019: 11) 
Dünya Bankası'nın bulgularına göre kitlesel fonlama ile girişimcilere aktarılan fonların 2025 yılında 90 milyar USD'ye ulaşması hedeflenmektedir. Bu hedeflerin gerçeklemesi ihtimalinde kitlesel fonlamanın dünyadaki toplam girişim sermayesi hacminin 1.8 katı büyüklüğünde bir gelişim trendini göstermiş olacaktır. Bu bağlamda, en büyük potansiyelin Çin'de olduğu, Çin'i sırasıyla Doğu Asya, Orta Avrupa ve Latin Amerika'nın takip edeceği öngörüler arasındadır (The World Bank, 2013: 43).

\section{Kitle Fonlaması'nın İşleyiş Mekanizması}

Kitlesel fonlama sistemi farklı model çeşitlerine sahip olmasına karşın, her bir proje bazında temelde belirli tek bir amacı olan ve bu amaca yönelik önceden saptanan miktardaki fonun yine önceden belirlenmiş bir zaman dilimi içinde toplanılmasının hedeflendiği karakteristik bir yapıya sahiptir (İşler, 2014: 54). Sistemin üç temel ayağı veya başka bir ifade ile üç aktörü vardır. Bunlar; fon arayanlar, fon sağlayanlar ve internet platformlarıdır.

Fon Arayanlar; tasarlayıp geliştirdikleri ürün veya hizmeti gerçekleştirmek için sermaye bulmaya çalışan girişimciler, Fon Sağlayanlar; girişimcilerin yapmak istedikleri projeleri finansal olarak destekleyen yatırımcı veya bağışçılar, İnternet Platformları; fon arayanlar ile fon sağlayanların iletişimini temin ederek bunları bir araya getiren internet tabanlı web siteleridir (Karaaslan ve Altuntaş, 2015: 490). Özellikle kitlesel fonlama platformları, girişimcilere küresel sahada iş fikirlerini değerlendirebilecekleri imkanı sağlamaları açısından sorumlulukları ve görevleri kuşkusuz çok önemlidir.

Kitlesel fonlama sisteminin sağlıklı ve güvenilir bir şekilde işleyebilmesi için her bir paydaş tarafından atılması gereken adımlar ve dikkat edilmesi son derece önemli olan işlevler aşağıda basamaklar halinde sistematik olarak özetlenerek sıralanmıştır.

\section{a. Fon Arayanlar Tarafindan Yapılması Gerekenler}

- Zihinlerindeki projelerini fikir seviyesinden bir ürün veya hizmet seviyesine geçirebilmek için olası maliyetlerini, platform komisyonlarını ve karşılaşabilecekleri riskleri de dikkate alarak projelerinin optimal bütçesini belirler,

- Belirlenen bütçeye hangi sürede ulaşılmasını istediğini tayin ederek iş planını hazırlar, platformu seçer,

- Alternatif internet platformlarını detaylı olarak inceleyerek kendi projeleri için rasyonel

- Bütçe hedefini, zaman aralıklarını, fon sağlanması istenilen ürün ya da hizmetle ilgili ayrıntılı bilgileri seçtiği platforma fon talebiyle birlikte ileterek yatırım imkanını oluşturur,

- Sağlayacak fon karşılığında verilecek ödül, kâr veya hisse payını net olarak tanımlar,

- Projenin kabul sürecinden sonra projesini tanıtmak için platformun sağladığı imkanları kullanarak projenin ortaya çıkış olgusu, hedeflerini, projenin özgünlüğünü açıklayan, görselliği yüksek bir kampanyanın çerçevesini şekillendirir,

- Fonun platform tarafindan fon arayana aktarılması için toplanan paranın hedef bütçenin isabetli olarak tutturulması için projenin tanınırlığını artırmak amacıyla Twitter, Facebook, LinkedIn vb. sosyal medya ağlarıyla etkin bağlantı kurar,

- Proje hakkında geri dönüşüm alarak kalitesini ve başarı şansını geliştirmek için potansiyel kullanıcılarla bir iletişim kanalı tesis eder,

- Proje sahipleri online platformda fon verenleri bilgilendirmek için sürecin ilerleyişiyle ilgili bilgileri sürekli olarak revize ederek günceller, 
- Fonun toplanması sonrası, fon karş1lı̆ında verecekleri ödül, kâr veya hisse payı alınarak projesi için gerekli fona sahip olur (Vural ve Doğan: 2019: 91; Ramos, 2014: 13).

\section{b. Fon Sağlayıcılar Tarafından Yapılması Gerekenler}

- Fon arayanların projelerinden internet platformu veya sosyal medya vasıtasıyla iletişime geçerek bilgi sahibi olur,

- Alternatif projeleri titizlikle etüd ve değerlendirmeler yaparak olası projeyi seçer,

- Mevcut platformlar aracılığıyla söz konusu fonun ödemesini yaparak belirledikleri projeye destek verirler,

- Verilen destekle birlikte kullandıkları sosyal medya araçlarıyla projenin kamuoyunda tanıtımına da katkı sağlarlar,

- Fon için yapılan ödeme karşılığında fon arayanın önceden taahhüt ettiği ödül, faiz geliri veya hisse payına sahip olurlar.

\section{c. İnternet Platformları Tarafindan Yapılması Gerekenler}

- Kitle fonlaması modelinde kullanılmak üzere; proje ve spesifik özellikleri tanıtma, video yayınlama, fon sağlayanlarla etkin iletişime geçme, projelerin internet sayfasındaki hareketliliği inceleme ve fonun toplanması konusuyla ilgili arayanlara aktarımı sağlamak amacıyla ödeme sistemlerine entegrasyon için aktif bir sanal alanı oluşturur,

- Kendilerine başvuran fon arayanların projelerini detaylı olarak inceler,

- Platformların bazılarının ön seçim süreçleri olabilir. Bu durumda projeye onay vermeleri sonrası oluşturdukları kampanya tanıtımlarını sitelerinde yayınlarlar,

- Platformlar, fon arayanların projelerinin ayrıntılı bilgileri ve fon karşıllı̆ında neler elde edeceği konusunda fon sağlayanları ve komisyonları ile ilgili fon arayanları sağlıklı olarak bilgilendirir,

- Fon arayanların başvurmaları ve fon sağlayanlar arasındaki iletişimi kurması sonrasında, fon sağlayanlar projeyi desteklemeye karar verince oluşturdukları güvenli ödeme sistemini kullanarak ödemeleri toplarlar,

- Toplanan fonlar proje için hedeflenen bütçe tutarına ulaştığında, daha önce belirlenen komisyonlar toplanan fonlardan tahsil edilerek kalan bakiye fon arayanların hesaplarına yatırilır (Vural ve Doğan: 2019: 91).

\section{Kitle Fonlaması Modelleri ve Temel Özellikleri}

Literatürde çerçevesinde dünyada uygulanmakta olan kitlesel fonlama modellerine bakıldığında farklı bakıș açılarından ve beklentilerden kaynaklanan çeșitli isim ve sınıflandırmaların olduğu görülmektedir (De Buysere vd., 2012: 2). Ancak uygulamada çok yaygın olarak kullanılan şekliyle kitle fonlaması modelleri temelde finansal olmayan ve finansal fonlama olmak üzere iki sinıfa ayrilmaktadır. Finansal olmayan fonlama, projelere destek verenlerin herhangi bir finansal beklenti içinde olmadıkları fonlama türü olup ödül ve bağış esaslı fonlama olmak üzere kendi içersinde iki farklı uygulaması vardır. Finansal olan fonlama ise projelere destek çıkanların, bunu aynı zamanda bir yatırım olarak değerlendirdikleri, finansal bir kazanç beklentisi içinde oldukları bir yatırım modeli olup borçlanma ve ortaklık olmak üzere kendi içerisinde iki uygulama türü bulunmaktadır (Atsan ve Erdoğan, 2015: 302). Toplamda bu dört fonlama modelindeki tasnifler, hem arz hem de talep yönelimli kullanıcıların motivasyonuna, diğer bir ifade ile yatırımcının geri dönüş beklentisine ve fonlananın fonu kullanım beklentisine dayanarak oluşturulmuştur. Projelere destek olmak isteyen katılımcılar ödül, bağış, borçlanma veya ortaklık karşılığı fonlama alternatiflerinden 
birisiyle yatırımlarını gerçekleştirmekte, öte yandan projeleri olan katılımcılar toplamak istedikleri fonun kullanım amacını ve miktarını da göz önünde bulundurarak bu seçeneklerden kendi motivasyonlarına en uygun olanını tercih ederek projelerini halka sunmaktadır (Sakızlı, 2018: 10).

\section{1. Ödül Temelli Fonlama Modeli}

Kitle fonlaması modelleri arasında oldukça sık kullanılan ödül temelli fonlama modelinde herhangi bir menkul kıymetin alınıp satılması söz konusu değildir. Bu modelde projesi için fon toplayan birey veya işletme, projesinin arzu edilen başarıya ulaşması halinde önceden taahhüt edilerek belirlenmiş bir ödülü fon sağlayıcılara vermeyi söz vermiştir (Onur ve Değirmenci, 2015: 2). Taahhüt edilen bu ödül, teşekkür ederim telefonundan, bir T-shirt veya kitap armağanına veya bir kitabın önsözünde katkı verenlerin isimlerinin geçmesine kadar geniş bir yelpazede olabilmektedir (Atsan ve Erdoğan, 2015: 302)

Ürün fonlama amacıyla yapılan ödül temelli fonlama, uygulamada daha çok sanat, müzik ve tasarım, teknoloji, sinema ve eğlence sektörlerini kapsayan projeler veya ürünler için kullanılmaktadır (Ziegler vd., 2018: 21). Ödül temelli kitle fonlamasında, fon aktarımı sırasında herhangi bir sermaye piyasası aracı kullanılmadığından, internet sitesi aracılığıyla gerçekleşen bu işlemler aracılık veya yatırım danışmanlığı olarak kabul edilmez. Aktarılan kaynaklar karşılığında verilebilecek ürünler Sermaye Piyasası Kurulu'nun her türlü finansal işlemler için belirlediği yönetmeliğe uymak zorundadır ve yasaklı ürünler kesinlikle ödül olarak verilmemektedir.

Ödül temelli fonlama modelin yapısından kaynaklanan birtakım avantaj ve dezavantajları bulunmaktadır. Bu modelin diğer modellerden farklı olarak en büyük faydası, pazarlama ve piyasa araştırması konusunda sağladığı imkanlardır. Ödül temelli kitlesel fonlama modelinde temin edilmesi öngörülen ödüller genel olarak geliştirilmesi planlanan projenin bir çıktısı veya ürünün kendisi olduğundan, kitlelere yapılan ön sunum ve açık çağnı, proje sahibine bir bakıma gerekli etüdleri yapılmış ön piyasa araştırması sunmaktadır. Böylelikle proje sahibi, toplumda ürünün ne kadar talep edildiği veya bireyler tarafından ürüne ne kıymet takdir edileceği gibi kilit ve önemli dataları rasyonel bir şekilde kolaylıkla ve minumum maliyetle toplamaktadır (Sakızlı: 2018: 13). Diğer taraftan, söz konusu modelinin aşağıda maddeler halinde sıralandığı gibi bazı dezavantajlı tarafları da bulunmaktadır: belirsizliği,

- Taahhüt edilen ödül fon sağlayıcıya teslim edilmediğinde sorumlunun kim olacağının

- Projenin, proje sahiplerinin önceden açıkladığı şekilde yürütülmemesi durumunda kimin sorumlu olacağının belirsizliği,

- Toplanan fonların geri ödenmesi gerektiğinde işlemlerin nasıl yürütüleceğinin net olmamas1,

- Geniş bir kitleye sunulan bir proje veya ürün olmadıkça gerekli finansman tutarının sağlanmasının son derece güç olması,

- Ayrıca bu modelin uygulanmasına her ülkenin menkul kıymetlere ilişkin mevzuatı izin vermemektedir. Menkul kıymet kanunları projeye yapılan katkıları risk sermayesi tanımı altında ele alıp menkul kıymet yatırımları olarak değerlendirebilmektedir (Onur ve Değirmenci, 2015: 2).

\subsection{Bağış Temelli Fonlama Modeli}

Günümüzde özellikle son yıllarda birçok ülkede görüldüğü gibi yeryüzünde fazlasıyla yaşanan sel, deprem, kasırga tarzı doğal afetler yanında kıtlık, hastalıkla mücadele ve benzeri acil durumlarda çeşitli kaynaklardan yardımlar toplanmaktadır. Bağış temelli fonlama modeli, İhtiyaç duyulan fonların bireyler tarafından projelendirilip internet üzerinden duyurulması sonrasında diğer 
kişiler tarafından yapılan bağışların kitle fonlaması organizasyonları aracılığıyla toplanması ve proje sahibine bu bağışların ulaştırılması şeklinde işlemektedir (Karaarslan ve Altuntaş, 2015: 490).

Bağış temelli fonlama modelinde, proje sahibinin yatırımcılara sağladıkları fon katkıları karşıllğında maddi veya gayri maddi herhangi bir getiri, rant veya menfaat temin edilmediğinden dolayı, aktarılan kaynak transferi destekçi tarafından bağış olarak değerlendirilir. Bu modelde yatırımcılar katkı sağlamak istedikleri projeden bir geri dönüş motivasyonu taşımamakla birlikte, kurallara ve proje türüne göre vergi indiriminden yararlanabilirler (Sakızlı, 2018: 11). Böyle projelere fon sağlayanlar tarafından finansal bir getiri talep edilmemekle birlikte beklentiye de girilmediğinden herhangi bir risk söz konusu değildir. Ancak proje sahiplerinin her zaman ve koşulda bu modelle arzu edilen miktarda fon toplaması oldukça güçtür (Onur ve Değirmenci, 2015: 2). Diğer taraftan, bağış temelli fonlama modelinde karşı karşıya kalınabilecek belki de en önemli risk, günümüzde oldukça artan finansal dolandırıcılık amacıyla yardım projelerinin sahte veya hayali olma olasılığıdır. Bu açıdan bakıldığında, modelin sağlıklı işleyebilmesi için internet site yöneticilerinin oldukça dikkatli davranarak, projelerin titizlikle incelendikten sonra gerekli görülen sorgulama ve sıkı takiplerle söz konusu muhtemel risklerin aşılabileceği söylenebilir.

\subsection{Borçlanma Temelli Fonlama Modeli}

Borçlanma temelli veya literatürde geçen diğer isimi ile yatırım temelli fonlama modeli, mikro-kredi sisteminin işlevini yerine getirerek, fon talebinde bulunan proje veya işletme sahiplerine kitlesel fonlama platformları aracılığıla, ihtiyaçları olan fon miktarına göre belirli bir vade tarihi ve faiz ödemesi çerçevesinde, fon sağlayıcılardan borç veya kredi şeklinde fon bulmasını sağlar. Konvansiyonel banka kredisiyle borçlanma yöntemine çok benzeyen, borçlanma temelli fonlama modelindeki temel farklılık, borcun bankalar yerine birden çok yatırımcıdan sağlanmasıdır (Sakızlı, 2018: 15). Bu model daha çok bankalardan kredi alabilmek için yeterli kredibiliteye veya teminata sahip olmayan bireyler veya küçük işletmeler tarafından tercih edilmektedir (De Buysere vd., 2012: 11). Borç verme bir kredi anlaşması yapılarak belirli bir faiz miktarı ve geri ödeme planı çerçevesinde borç verilmesi veya faizsiz ve geri ödemenin sadece işletmenin gelir veya kar elde etmesi şartına bağlı olarak borç verilmesi tarzında yapılabilmektedir (Zengin, Yüksel ve Kartal, 2017: 28).

Bu modelde de, diğer kitlesel fonlama türlerinde olduğu gibi sanal ortamda kurulmuş olan ve ödeme sisteminin sağlıklı bir şekilde işlemesini sağlayan platformlar kullanılmaktadır. Girişimci mevcut sistem çerçevesinde, hedeflediği fonlama tutarı için önceden belirlenen faiz ve vade koşulları ile tayin edilen belirli bir zaman diliminde potansiyel yatırımcılardan borçlanmayı hedefler. Hedeflenen fonlama tutarına erișildiğinde borçlanan kiși, katılımcılara verdikleri katkı tutarına ek olarak faiz geri ödemesi yapar. Kitleye dayalı bu yenilikçi borçlanma yapısı, geleneksel finansal sisteme kıyasla borçlanan taraf için masraf, borç veren için ise getiri anlamında yarar sağlamaktadır. Bunun temel nedeni, tasarrufların bir finans kuruluşu üzerinden yatırıma dönüştürülmesinde dosya masrafi, komisyon giderleri ve işletim ücretleri gibi maliyeti artıran bir dizi faktörün bulunmasıdır ( Sakarya ve Bezirgan, 2018: 26).

Borçlanma temelli fonlama modeli bir takım riskleri de beraberinde getirmektedir. Şöyle ki, söz konusu modelin konvansiyonel bankaların tasarruf hesaplarından daha fazla getiri taahhüdünde bulunması yatırımcı için cazip görünse de, yüksek faiz getirisinin oluşmasında yatırım riskinin olmasının yeri büyüktür. Her yatırım, kaynak sağlanan projenin kapsamına ve proje sahiplerinin ehliyetine göre belirli bazı riskleri beraberinde getirir. Özelikle kitle fonlaması sisteminin aktörleri tarafindan kullanılan platform veya piyasa internet sitelerin şeffaflığının kısıtlı olarak sağlanmasından kaynaklanan yüksek riskler mevcuttur. Sınırlı șeffaflığa neden olan faktörler Avrupa Bankacılık Otoritesi (European Banking Authority-EBA) tarafindan; yetersiz durum tespit değerlendirmesi, kredi notunun platform tarafından tespit edilmesi ve platformun çökme ihtimaline karş1 alınan tedbirlerin eksikliği olarak ifade edilmiştir. Diğer taraftan, diğer kitle fonlama modellerinde de olan proje temelli dolandırıcılık riski bu modelde de vardır. Örneğin platformda, 
proje veya işletme sahipleri yeterli durum tespiti ve proje etüd değerlendirmesinde bulunmaz ise, batmakta olan şirketlerin iflas öncesi bu modeli kullanarak finansman bulmasının önüne geçilemez. Eğer bu ve benzeri dolandırıcılıkların önüne geçilmek isteniyorsa, denetim ve kontrollerin oldukça sık1 ve titizlikle düzenlenmesi kuşkusuz zorunludur. Platformların proje veya işletme durum tespitini yapma sorumluluğu, yatırımcı algısını etkileyerek beraberinde ayrımcılık ihtimalini de barındırdığından, işletme durum tespiti görevi platformlara verilirken, platformların da denetlenmelerinin yapılması sistemin sağlıklı işleyişi için büyük önem arz etmektedir (Sakızlı, 2018: 16).

\subsection{Ortaklık Temelli Fonlama Modeli}

Ortaklık temelli fonlama modeli, literatürde ismi pay veya hisse temelli fonlama modeli olarak da geçmektedir. Genellikle finansmana ihtiyaç duyan girişimci tarafından ihtiyaç duyulan fon tutarı belirli bir limit olarak belirlenir ve kitle fonlaması yoluyla optimal zamanda saptanan rakamın sağlanmasıyla yatırım gerçekleştirilir. Ortaklık temelli fonlama modelinde de fonun toplanacağ platform aracılığ ile yatırımcılarla işletmeye; işletmenin değerlemesine, iş planına, fonun olası kullanım şekline ve işletmenin ortaklık hisselerinin ne kadarının satışa sunulduğuna ilişkin muhtelif veri ve bilgiler paylaşılır. Bu model ile geniş bir yatırımcı kitlesine ulaşılarak oldukça yüksek tutarlarda finansman sağlanabilir. Ülkelerin mevzuatlarındaki düzenlemelerine göre değişiklik göstermekle birlikte, bu modelle finansman sağlayan işletmeler halka açık işletmelerden farklı düzenlemelere tabi tutulmaktadır (Onur ve Değirmenci, 2015: 3).

Ortaklık temelli fonlama modelindeki işleyiş mekanizması, hisse senedi piyasası ile benzerlik ve paralellik göstermektedir. Projenin başarılı bir şekilde hayata geçirilmesinin ardından getirinin artması, diğer potansiyel yatırımcıların da ilgisini çekecek ve piyasanın proje üzerinde oluşturacağı talep hisse fiyatının yükselmesine neden olacağından kitlesel fonlama aşamasında projeye ortak olan kişilerin finansal getiri kazanmasını sağlayacaktır. Öte yandan, bu tür modelin geleneksel hisse senedi piyasasından ayrılan temel ayrılı̆̆ finansman ihtiyacına ulaşılıp ulaşılamayacağıdır. Diğer bir ifadeyle, projeye ortak olan yatırımcı, projenin hayata geçmemesi ile katılımda bulunduğu tüm yatırımını kaybetme riski ile karşı karşıya kalma ihtimalidir (İşler, 2014: 57).

$\mathrm{Bu}$ fonlama modeli aynı zamanda yeni girişim (start-up) veya inovasyon ekosisteminin bir parçası olarak öz sermayeye katkı sağlayan bir finansman bulma alternatifidir. Gerçekleştirilen, kitlesel fonlama işlemlerinde ortaklık, hisse veya pay şeklinde verilebileceği gibi kar paylaşımı (profit-sharing) tarzında, projenin veya işletmenin ilerideki vadelerde karlılığından verilecek paylar şeklinde de yapılabilmektedir. Kar paylaşımı ile yapılacak geri ödeme anlaşmaları işletmenin veya projenin kârlılığına dayandığından dolayı, fon toplayan taraf için büyük bir esneklik sağlar ve yatırımcı ile proje sahibini aynı hedef doğrultusunda, daha fazla kârlılık için, çalışmaya teşvik eder.

Genel olarak bakıldığında söz konusu model de diğer yatırım temelli kitlesel fonlama uygulamaları gibi, daha yüksek getirili yeni bir varlık sınıfına yatırım imkânı sağlar ve aynı zamanda girişimcilerin daha farklı alternatif finansman kaynaklarına ulaşımına aracılık eder. Bu modelin önemli özelliklerinden birisi olarak, muhtemel kar tahminlerinin önünde belirli bir tavan limitinin bulunmaması olarak gösterilebilir. Eğer fonlanan girişim veya proje gelecekte piyasanın lider bir işletmesi olursa, yatırımcı aktardığı kaynağı sınırsız şekilde katlayabilir. Bundan dolayıdır ki hem işletme veya proje sahiplerinin hem de yatırımcının temel hedefi, diğer kitlesel fonlama yöntemlerine kıyasla aynı düzlemde yer alır. Yatırımcı için bu cazip fırsatı sunan yöntem ayrıca fon toplayanın yatırımcıya daha kısıtlı sorumluluk vermesini sağlar. Bu sayede işletme sahipleri, risk sermayedar piyasasına kıyasla, hem daha az hisse veya ortaklık paylaşırken, yani daha az maliyetle karşılaşırken, hem de şirketin kontrolünden sermaye karşıllı̆ında daha az feragat etmek zorunda kalır.

Bu modelin büyük yatırımlarda kullanılmasından kaynaklanan yüksek iflas riski yanında diğer bir muhtemel risk olarak likidite problemi de gösterilmektedir. Likidite riski, fon karşıllı̆̆ hisse 
paylaşımı yapılan işletmenin hisselerinin alınıp satılması için ikincil bir piyasanın bulunmamasından kaynaklanmaktadır. Bunun başlıca nedeni olarak, ortaklık yapısı değişen işletmelerin hisselerinin fonlama işlemi öncesi halka açık olmaması durumunda hisselerinin ticaretinin Sermaye Piyasası Kurulu kararınca mümkün olmamasıdır. Ayrıca EBA'nın belirttiğine göre bu modelle yatırım alan şirketlerin genel olarak erken dönem ve büyüme odaklı olması, yatırımcının hissesini satabilecek pozisyona gelene kadar hiçbir ödeme alamama riskine yol açabilmektedir. Buna ek olarak yeni girişimlerde ilk finansmandan sonraki dönemlerde dağıtılacak hisselerin, ilk yatırımcının sahip olduğu payları seyreltmesi bu sistemin cazibesini düşürmektedir. Diğer bir neden ise fonlama sonrası çoklu ortaklıkta sahip olunacak hisselerin veya payın yatırımcı başına düşük miktarlı olacağından dolayı, yatırımcının durum tespit analizini kapsamlı olarak yapması için bir motivasyonu olmadığından risklerin bu modelde fazlasıyla yüksek olması olarak gösterilmektedir. Buna ek bazı eleştirilere göre, başlangıç seviyesindeki firmalara yapılacak durum tespit analizlerini belirli bir standarda oturtmak oldukça karışı olduğundan, genelde risk sermayedarlarının incelediği; değerleme, tasfiye tercihleri, azınlık korumaları, bilgi hakları, bırakma hükümleri, ilk ret hakları, anti-tasfiye, tersine hak kazanma gibi teknik kavramların kullanılması bir tarafa anlaşılması bile bir uzmanlık gerektirmektedir (Sakızl1, 2018: 17-18).

\section{Türkiye'de Kitle Fonlaması ve Gelişimi}

Dünyada etkin olarak 1990'lardan itibaren uygulanmakta olan kitle fonlaması, ülkemizde 2010 yılında kurulan kitle fonlaması platformu ile uygulanma sahasına girmiştir. Aralık 2016 tarihinde ise Türkiye'deki girişimciler ve yeni projelerin desteklenmesi için alternatif finansal platform olarak kitlesel fonlamanın yaygınlaşmasını misyon edinen ilk kitlesel fonlama derneği kurulmuştur. Derneğin temel amacı, oldukça az sayıda ve genellikle ödül ve bağış temelli olan kitlesel fonlama platformlarına yeni platformların eklenmesini sağlamaktır. Ayrıca dernek, Türkiye'de kitlesel fonlamanın bilinirliğini arttırmanın yanı sıra hukuki çerçevesinin oluşturulmasına da katkıda bulunmayı amaçlamaktadır (Ekonomistler Derneği, 2019: 11).

Ülkemizde ilk yıllarda düzenleyici altyapının sadece ödül ve bağış şeklinde fon temin edilmesine imkân tanıması nedeniyle bu alanda arzu edilen gelişme trendinin yakalanamadığı gözlenmiştir (Kıran, 2013: 1). Özelikle bağış temelli modelin uygulanmasında bir takım yasal engeller nedeniyle önemli problemlerle karşılaşılmıştır. Şöyle ki, yalnızca kamu yararına uygun olarak amaçlarını gerçekleştirmek, muhtaç kişilere yardım sağlamak ve kamu hizmetlerinden bir veya birkaçını gerçekleştirmek veya destek olmak üzere gerçek kişiler, dernekler, vakıflar, spor kulüpleri, gazete ve dergilerin yardım toplamasına izin verilirken diğer tüzelkişi ortaklıkları (internet platformları) ve girişimcilerin yardım veya bağış toplaması yasal düzenlemelere takılmaktadır (Atsan ve Erdoğan, 2015: 302). Ayrıca ilk zamanlarda, sağliklı bilgi eksikliği ile birlikte yasal düzenlemelerdeki boşluklar ülkemizde kitle fonlamasının gelişimini olumsuz etkilemiştir.

5 Aralık 2017'de 30261 say1lı Resmi Gazetede yayınlanan 7061 sayılı Kanun kapsamında 6362 Sayılı Sermaye Piyasası Kanunu'nda gerçekleşen değişiklik ile ülkemizde kitle fonlaması Sermaye Piyasası Kanunu himayesine alınarak yasal olarak kabul edilirken aynı zamanda ortaklık temelli fonlama modeli de uygulama sahasına girmiştir (Resmi Gazete, 2017). Böylelikle kanun koyucu kitlesel fonlama platformlarını serbest piyasa düzeni içerisinde yasal çerçevede çalışma zemininin sınırlarını bir takım denetim ve koruma mekanizmaları içerisinde çizmiştir. Söz konusu kanun çerçevesinde yapılan düzenlemeleri maddeler halinde şu şekilde özetleyebiliriz:

1- $\quad$ Kitle fonlaması, Sermaye Piyasası Kanunu tarafindan düzenlenecek esaslara göre girişimcilerin ihtiyaç duydukları finansmanı sağlamak için kitle fonlaması platformları aracılığı ile Sermaye Piyasası Kanunu'nun yatırımcı tazminine ilişkin hükümlerine tabi olmadan para toplanması olarak tanımlanmışdır,

2- $\quad$ Finansman sağlayan ortaklıkların küçük ölçekte olmaları nedeniyle kurumsal yapılarının halka açık ortaklıkların yapılarına sahip olmaması gerektiği daha önce kanun tasarısında 
vurgulanmıştır. Düzenlemede de kitle fonlaması "halka açık ortaklık" ve "ihraççı" tanımlamalarından ayırılmışıır,

3- Kitle fonlaması yöntemiyle halktan para toplama görevi kitle fonlaması platformlarına verilmekle birlikte, diğer kanunların yardım ve bağış toplanmasına ilişkin hükümleri saklı bırakılmıştır,

4- Kitle fonlaması platformları, halka açık ortaklık ve ihraççıların tabi oldukları yükümlülüklerden muaf tutulmuşlardır,

5- $\quad$ Kitle fonlaması yöntemiyle halktan para toplayan ortaklıkların pay sahibi sayısı beş yüzü aşsa bile halka arz sayılamayacağı kabul görmüşdür,

6- Kitle fonlaması platformları, Sermaye Piyasası Kurulu'ndan izin alarak kurulan ve elektronik ortamda kitle fonlaması için aracılık hizmeti veren kuruluş olarak tanımlanmıştır. Kitle fonlaması platformlarına ilişkin kuruluş kuralları, izinleri, uygulama esasları ve fon limitleri, kontrol ve denetim ile ilgili esasları Sermaye Piyasası Kurulu tarafından düzenlenecektir. Hukuka aykırı faaliyet ve işlemlere ilişkin tedbirlerin de Sermaye Piyasası Kanunu'nun 96. hükümlerine kıyasen uygulanması gerektiği ifade edilmişdir,

7- $\quad$ Kitle fonlaması ve buna bağlı olarak yapılacak işlemler ile ilgili kitle fonlaması platformları, piyasa işleticileri, teşkilatlanmış diğer pazar yerleri ve borsalarla ilgili Sermaye Piyasası Kanunu hükümlerine tabi tutulmamıştır,

8- Kitle fonlaması platformları, fon sağlayan ve fon arayan tarafları arasındaki ilişkilerin genel hükümlere tabi olacağı hükme bağlanmıştır. Buna göre bu ilişkiler Sermaye Piyasası Kanunu'nda ayrı bir maddede düzenlenmemiş olup taraflar arasındaki ilişkiler özellikle Türk Borçlar Kanunu ve Türk Ticaret Kanunu'nun genel hükümlerine tabi bırakılmıştır,

9- $\quad$ Sermaye Piyasası Kurulu'nun izni olmadan kitle fonlaması platformlarının para topladığı, yurt dışında kaldıraçlı işlem veya türev araç işlemleri yaptığı belirlendiği takdirde Sermaye Piyasası Kurulu'nun başvurusu ile platformun internet sitesine erişimi Bilgi Teknolojileri ve İletişim Kurumu tarafından engelleneceği karar bağlanmıştır.

2017 yılında yapılan kanun değişikliği ile ülkemiz mevzuatına girmiş olan kitle fonlamasının yasal altyapısına yönelik Sermaye Piyasası Kurulu tarafından hazırlanan daha ayrıntıları içeren ikincil mevzuat düzenlenmesi, 3 Ekim 2019 tarihli ve 30907 sayılı Resmi Gazete'de yayımlanarak yürürlüğe girmiştir. İkincil mevzuat düzenlemesinde üzerinde önemle durularak vurgulanan hususları ana hatlarıyla şu şekilde özetleyebiliriz;

Yeni iş kuran girişimciler, geleneksel bankalardan uygun koşul ve şartlarda temin edemedikleri finansal erişimlere kitle fonlaması yöntemiyle ulaşabileceklerdir. Bireysel yatırımcılar da tek başlarına kayda değer bir etki oluşturmayan küçük tutardaki fonlarını birleştirerek bir işletmenin hayata geçmesini sağlayabilecektir. Böylece yatırımcılar gelişme potansiyeli olan bir şirkete kuruluş aşamasında ortak olma firsatını elde etmiş olacaklardır.

Buna göre, başlangıç aşamasındaki girişimler sermaye ihtiyacını gidermek için halktan para toplayabilecektir. Böylelikle ekonomik kalkınmayı destekleyici potansiyele sahip yenilikçi ve teknoloji odaklı girişimlerin hayata geçirilmesine gerekli şartlar sağlanmıştır. Yenilikçi ve katma değere dayalı iş modeli bulunan işletmelerin yararlanması amacıyla yalnızca Tebliğ'de tanımlı teknoloji ve üretim faaliyetini gerçekleştiren veya gerçekleştirecek olan girişimlere kitle fonlaması imkânı tanılacaktır.

Girişimciler ile bireysel yatırımcılar internet üzerinden bir platformda buluşacaktır. Sadece Sermaye Piyasası Kurulu'nun faaliyet izni verdiği ve listesine aldığı platformlar kitle fonlamasına aracılık edebilecektir. Dolayısıyla, her türlü girişim kitle fonlamasından faydalanamayacaktır. 
Aracılık eden platformların kendi bünyelerinde oluşturacakları en az üçer kişilik yatırım komitelerinin inceleyeceği ve kriterlere uygun girişimler fon toplayabilecektir. Ayrıca muhtemel kayıpların sınırlı düzeyde kalması amacıyla, yatırımcılar bir yıl içinde en fazla yirmi bin lira yatırım yapabilecektir. $\mathrm{Bu}$ limit yatırımcının gelir düzeyine bağlı olarak yüz bin liraya kadar artırılabilecektir. Yatırımcıların haklarını gözeten kurallar ve denetimler sayesinde insanların saadet zincirlerinin tuzağına düşerek mağdur olmasının da önüne geçilebilecektir (https://www.spk.gov.tr).

Girişimcilerin geliştirdikleri projelerini reel sektörde hayata geçirebilmelerinde karşılarına çıan ilk engellerden birisi finansal kaynak sorunudur ( Cosh vd., 2009: 1496). Dikkat edilirse söz konusu yapılan yasal düzenlemeler, borçlanma temelli kitle fonlamasını kapsamamaktadır. Halbuki dünyada girişimcilerin ihtiyaçları olan fona daha kolay, hızlı ve optimal maliyetle ulaşabilmeleri için en çok rağbet gören ve en yüksek fonu sağlayan model borçlanma temelli kitle fonlaması modelidir (Vural ve Doğan, 2019: 89). Ülkemizde son yıllarda hazırlanan Kalkınma Planları ve Yeni Ekonomi Programları çerçevesinde özellikle girişimcilerin en önemli sorunları arasında gösterilen yüksek maliyetli ve kıt alternatif finansal kaynak sorununun aşılması açısından yenilikçi enstrümanlar teşvik edilmektedir. Yeni dönemin finansal araçlarından olan kitlesel fonlama modelinin daha etkin ve verimli şekilde kullanılması için borçlanma temelli fonlama modelinin de ülkemiz koşullarına uygun olarak yasal mevzuat kapsamına alınarak işlerlik kazandırılmasının uygun ve yerinde bir karar olacă̆ 1 söylenebilir.

Ayrıca Türkiye'de kitlesel fonlama uygulaması, henüz sınırlı sayıda internet sitesi tarafindan uygulanmaktadır. Ülkemizde kısıtlı verilerden elde edilen bilgiler çerçevesinde yapılan az sayıdaki araştırma bulgularına göre de kitle fonlaması uygulaması özellikle diğer ülkelerle karşılaştırıldığında emekleme aşamasında bulunmaktadır (Sakarya ve Bezirgan, 2018: 30). Bu açıdan bakıldığında, kanun yapıcılar tarafindan ülkemizdeki girişimciler için oldukça cazip alternatif bir finansal yöntem olarak görülen kitle fonlaması hakkında kamuoyunda sağlıklı bilgi ve tanıtım faaliyetlerinin etkin bir şekilde yapılması zorunludur. Ayrıca ülkemizde Yeni Ekonomi Programlarında yer alan kitle fonlaması eylem planları hakkında girişimcilerin ivedilikle haberdar edilerek yeterli seviyede yönlendirilip desteklenmesi kuşkusuz son derece önemlidir.

\section{Sonuç}

Girişimcilerin en önemli sorunları arasında kuşkusuz optimal maliyetli ve zamanında finansal kaynak bulmak handikapıdır. Dünyadaki ülkelerin yasal otoriterleri bu sorunun çözüme kavuşması amacıyla hukuksal, finansal ve teknik açılardan farklı desteklemeler veya teşvikler yapmaktadır. Ülkemizde de özellikle son yıllarda ekonomik kalkınmanın lokomotifi olarak görülen girişimcilerin sayılarının artırılması ve karşılaşabilecekleri sorunların giderilmesi için ciddi adımlar atılmaktadır. Bu adımlardan birisi de T.C. Hazine ve Maliye Bakanlığı tarafından hazırlanmış olan 2020-2022 yıllarını kapsayan Orta Vadeli Yeni Ekonomi Programıdır. Yeni Ekonomi Programı'nın finansal istikrar ana başlığında, program dönemi boyunca finansal istikrarın sağlanarak güçlendirilmesi amaciyla politika ve tedbirler alt başlı̆̆ında yapılacaklar sistematik olarak sıralanmıştır. Söz konusu politika ve tedbirlerden birisi de girişimcilerin finansman sorunlarına çare olabilecek, dijital dönüşüm teşvik edilerek yenilikçi projelerin finansmanı için kitle fonlaması (crowd funding) adı altında çağdaş yeni nesil bir finansman kanalı oluşturmak hedeflenmektedir.

Kitle fonlaması finansman yöntemi, finansal kaynak bulmada sorun yaşayan girişimcilerin ihtiyaçları oldukları fonları geniş kitlelerin küçük miktarlardaki fonlarını bir araya getirerek oluşturdukları fon toplama yöntemi olarak ifade edilebilir. Dünyada farklı uygulamaları olmakla birlikte, genelde kitle fonlamasının bağış temelli, ödül temelli, borçlanma temelli ve ortaklık temelli olmak üzere dört farklı türü bulunmaktadır. Ülkemiz girişimcileri için önemli bir alternatif finansman yöntemi olacağı öngörülen kitle fonlaması yöntemi dünyada 1990'lı yılların sonlarından itibaren uygulanmaktadır. Türkiye'de ise 2010 yılında küçük boyutlarda uygulama sahasına girmiştir. Kitle fonlamasının yasal zeminde ve güvenilir etkin bir şekilde yaygın olarak işlerlik 
kazandırılması amacıyla, Sermaye Piyasası Kurulu tarafından 5 Aralık 2017 ve 3 Ekim 2019 tarihlerinde iki mevzuat düzenlemesi yapılmıştır.

Kitle fonlamasının ülkemiz girişimcilerinin projelerinde arzu edilen düzeyde aktif olarak kullanılabilmesi için aşağıdaki tespitlerimizin dikkate alınarak gerekli görülen düzenlemelerin ve faaliyetlerin ivedilikle yapılmasının doğru olacağı düşünülmektedir.

1- Kitle fonlaması yöntemi dünyada yaygın olarak kullanılıp tanılınırken ülkemizde farkındalığı oldukça düşük bir fenomendir. Bu açıdan bakıldığında, girişimcilerin kitle fonlaması hakkında uzman kişi ve kurumlar tarafından sağlıklı ve güncel bilgilerle donatılması amacıyla seminerler, toplantılar yapılması, tanıtıcı broşür ve kitapçıklar hazırlanarak kamuoyuna dağıtılması yerinde bir faaliyet olacaktır.

2- Kitle fonlaması modelinin yasal statüye kavuşturulması son derece önemli bir gelişmedir. Sermaye Piyasası Kurulu tarafindan yapılan kitle fonlaması yasal mevzuat düzenlemeleri günün şartlarına ve gelişmelere paralel olarak yeniden gözden geçirilerek gerekli görülen revizelerin zaman kaybedilmeden yapılması modelin uzun vadede sağlık gelişmesi açısından kuşkusuz oldukça önemli ve zorunludur.

3- Dünya'da girişimciler tarafından yaygın olarak kullanılan borçlanma temelli kitle fonlaması modeli ülkemiz mevzuatında yer almamaktadır. Kanun yapıcılarca, söz konusu modelin profesyonel olarak başarılı olarak kullanıldığ 1 tecrübeli ülkelerle iletişime geçilerek ülkemiz koşullarına adaptasyonun sağlanması derecesinde potansiyel girişimcilerin sayısını artıracağı beklenebilir.

4- Kitle fonlaması, fintec yansımalarından birisi olması açısından internet üzerinden finansal dolandırıcılıklara açık riskler taşımaktadır. Dolayısıyla kanun koyucuların kitle fonlaması uygulamasındaki etkin denetimleri ve yaptırımları pratikte tesis etmeleri sistemin güven içerisinde çalışmasını kolaylaştırarak potansiyel girişimcilerin sayısının artmasını pozitif olarak etkileyecektir.

5- $\quad$ Türkiye'de mevcut kitle fonlaması platformları sayısı ve proje işlem hacimleri hakkında sağlıklı bilgiler bulmakta oldukça güçlük çekilmektedir. Bu durum kitle fonlamasının taraflarınca sui istimalleri ve dolandırıcılıkları de beraberinde getirebilecektir. Ayrıca ülkemiz akademik yazında da kitle fonlaması başlıklı ampirik araştırma çalışmaları son derece azdır. Rasyonel analiz ve değerlendirmelerin yapılması için de sağlıklı verilere ihtiyaç bulunmaktadır. $\mathrm{Bu}$ açıdan bakıldığında, kanun koyucuların başkanlığında; kitle fonlaması faaliyetleri, işlem hacimleri, proje türleri hakkında detaylı network oluşturularak kamuoyunda paylaşılması kitle fonlamasının etkin ve verimli şekilde yaygınlaşmasına katkıda bulunacağı söylenebilir.

Kitle fonlaması ana temalı bundan sonraki yapılacak akademik çalışmalar, Sermaye Piyasası Kanunu'ndaki yer alan yeni düzenlemelerin ve Yeni Ekonomi Programında özellikle teşvik edilen kitle fonlaması modelin girişimciler üzerindeki etkisi çerçevesinde elde edilen bulgularla şekillenen torik veya ampirik özgün çalışmalar olabilir.

\section{Kaynakça}

Atsan, N. ve Erdoğan, E. O. (2015). Girişimciler için alternatif bir finansman yöntemi: Kitlesel fonlama (Crowdfunding), Eskişehir Osmangazi Üniversitesi İktisadi ve İdari Bilimler Dergisi, 10(1), 297-320.

Bağış, B. (2019). Yeni Dönemin Finansman Araçları, SETA Yayınları.

Beaulieu, T., Sarker, S. and Sarker, S. (2015). A conceptual framework for understanding crowdfunding, CAIS. 
Cosh, A., Cumming, D., Hughes, A. (2009). Outside Entrepreneurial Capital, The Economic Journal, 119, 1494-1533. https://doi.org/10.1111/j.1468-0297.2009.02270.x

Çubukçu, C. (2017). Kitlesel fonlama: Türkiye'deki kitlesel fonlama platformları üzerinden bir değerlendirme. Girişimcilik ve İnovasyon Yönetimi Dergisi, 6 (2), 155-172.

De Buysere, K., Gajda, O., Kleverlaan, R., Marom, D. ve Klaes, M. (2012). A framework for European crowdfunding, European Crowdfunding Network.

Ekonomistler Derneği. (2019). Girişimciliği Destekleyen Yeni Finansal Enstrümanlar.

İşler, S. T. (2014). Modern finansmanda yeni bir dönem: Kitlesel fonlama-Crowdfunding, Gösterge, Türkiye Sermaye Piyasaları Birliği (TSPB) Yayını. Güz Dönemi, 50-65.

Karaarslan, M. H. ve Altuntaş, B. (2015). Sosyal pazarlamanın yeni aracı: Kitle fonlaması. 20. Ulusal Pazarlama Kongresi Bildiri Kitab1, Anadolu Üniversitesi.

Kıran, T. (2013). Sermaye piyasalarında kitle fonlaması. Yeterlilik Etüdü. Sermaye Piyasası Kurulu Ortaklıklar Finansmanı Dairesi.

Mollick, E. (2012). The dynamics of crowdfunding. Journal Of Business Venturing, 29 (1), 1-16. https://doi.org/10.1016/j.jbusvent.2013.06.005

Onur, M. N. ve Değirmenci, Ö. (2015). Crowdfunding - Kitle Fonlaması. T.C. Başbakanlık Hazine Müsteşarlığı Çalışma Raporları. Sayı: 2015-7.

Ramos, J. (2014). Crowdfunding and The Role of Managers in Ensuring the Sustainability of Crowdfunding Platforms, Luxembourg: Publications Office of the European Union, Printed in Spain. https://publications.jrc.ec.europa.eu/repository/bitstream/JRC85752/jrc85752.pdf (Erişim tarihi: 11 Şubat 2020)

Resmi Gazete. (2017). Bazı Vergi Kanunları ile Diğer Bazı Kanunlarda Değişiklik Yapılmasına Dair Kanun.

Sakarya, Ş. ve Bezirgan, E. (2018). Kitlesel fonlama platformları: Türkiye ve yurtdışı karşılaştırması, Düzce Üniversitesi Sosyal Bilimler Enstitüsü Dergisi, 8 (2), 18-33.

Sakızlı, E. (2018). Alternatif Bir Finansman Yöntemi: Kitlesel Fonlama, İktisadi Kalkınma Vakfı Yayınları.

Solak, B. ve Faydal1, F. (2018). Girişimciler için kitlesel bir fonlama tekniği olarak kıckstarter örneği, 9. Girişimcilik Kongresi Bildiri Kitabı, Kırgızistan-Türkiye Manas Üniversitesi.

The World Bank. (2013). Crowdfunding's Potential for the Developing World, Washington. https://www.infodev.org/infodev-files/wb_crowdfundingreport-v12.pdf, (Erişim tarihi: 18 Şubat 2020)

Vural, A. ve Doğan, D. U. (2019). Girişimcilik finansmanında yeni bir model: Kitle fonlaması. İşletme Araştırmaları Dergisi, 11 (1), 88-100. https://doi.org/10.20491/isarder.2019.584

Zengin, S., Yüksel, S., Kartal, M. T. (2017). Kitle fonlaması sisteminin Türkiye'ye faydaları. Bankacılık ve Sermaye Piyasası Araştırmaları Dergisi, 1 (2), 22-32.

Ziegler, T., Reedy, E. J., Le, A. and Kroszner, R. S. (2018). 2017 The Americas Alternative Finance Industry Report. Cambridge University.

http://www.resmigazete.gov.tr/main.aspx?home=http://www.resmigazete.gov.tr/eskiler/2017/12/20 171205.htm\&main=http://www.resmigazete.gov.tr/eskiler/2017/12/20171205.htm (Erişim tarihi: 14 Ocak 2020) 
https://www.spk.gov.tr/Duyuru/Dosya/20191003/0 (Erişim tarihi: 04 Şubat 2020)

http://www.bumko.gov.tr (Erişim tarihi: 20 Şubat 2020)

https://medium.com/@halkyatirim/kitle-fonlamas\%C4\%B1-crowdfunding-nedir-404587878617

(Erişim tarihi: 21 Şubat 2020) 